\title{
An Investigation into the Current Situation of Urban Integration of Female Migrant Workers__A case Study of Yongkang City, Zhejiang Province
}

\author{
Kun Jing, Qifeng Sun, Lingxiao Liang \\ College of Economy and Trade Management, Quzhou University, Zhejiang, 324000
}

Keywords: manufacturing industry; 90 female migrant workers; urban integration; empirical analysis

\begin{abstract}
With the development of the new urbanization, a large number of agricultural surplus labor force into the city, forming an irreversible trend of "migrant workers". Among them, the proportion of female migrant workers increased year by year. This shows that the real and potential problems of female migrant workers will become the focus of social contradictions and public opinion in the future. In order to realise its level of integration into the city, the team selected more than 200 female migrant workers in the manufacturing industry in Yongkang as a social survey. Through the survey found that "education level", "monthly income", "whether there is a labor contract" and "the satisfaction of urban life" is the main factors affecting the urban integration of female migrant workers. Therefore, we recommend that the company take "on-the-job training", suggested that the government through the reform of the household registration system ", to speed up the female migrant workers into the city after 90 life rhythm, help to promote the new town construction.
\end{abstract}

\section{Introduction}

Through access to information, we found that the current academic study of female migrant workers into the city is still shallow, but are gradually becoming a hot spot. Although some scholars from the social aspects of the city life into the status qua, but with the topic of "the study of public groups of migrant workers" of the breadth and depth of the present stage compared to the relevant research data is still quite scarce, studies specifically for female migrant workers into the city of still stay in qualitative and level research the case, the lack of deep investigation. At the same time, the existing studies focus more on the material level and the constraints of the external objective conditions, and pay less attention to the influence of their spiritual level and individual psychological level on their urban integration. [1]

\section{Research program}

To master the migrant workers into the level of 90 female cities, to provide real data and reference to the relevant enterprises and government departments, and caused social concern to this group, the research group decided to carry out the social investigation. In order to smoothly carry out the investigation, we developed a detailed survey program, from the "individual character", "working conditions", "life" and "the city into four aspects respectively design the survey questionnaire and the interview outline.

The survey was carried out smoothly in Zhejiang, Yongkang in August 2016, the object of investigation for the local women engaged in the manufacturing of 90 migrant employees, sampling method for random sampling. In Zhejiang Province, the manufacturing industry is the main industry to attract foreign migrant workers. The number of alien population engaged in the manufacturing industry is one of the basic characteristics of Yongkang, which is called "hardware capital". According to statistics, as of the end of 2015, registered in Yongkang City. The floating population 
reached 531 thousand and 400 people. Gathered more than 1.4 local hardware machinery manufacturing enterprises, nearly 300 thousand employees. Therefore, our sample has some descriptive significance.

In this survey, the research team in Zhejiang, Yongkang, a total of 215 questionnaires issued, the ultimate recovery of the actual questionnaire of 198. Effective questionnaires were 140, and the recovery rate was $70.7 \%$.

In order to guarantee the quality of the questionnaire, the survey team also analyzed the reliability and validity of the questionnaire. The datum was analyzed by descriptive analysis, interactive analysis and regression analysis.

\section{Data analysis}

From the age point of view, the survey of 140 valid samples are between 15 to 27 years old, in line with the conditions of this investigation;

From the perspective of education, most of the female migrant workers' cultural level are only in junior high school education, accounting for $45.72 \%$ of the total sample. This result is in line with China's latest "2015 monitoring report" [2] in the education of migrant workers in the data;

From the monthly income situation, most of the manufacturing of 90 female migrant workers in a monthly income of 2000 to 3000 , accounting for $43.57 \%$ of the proportion of the overall sample, with income of migrant workers this month manufacturing industry with the data in the report;

From the experience of growth and education experience, some 90 female migrant workers grew up in the countryside, but then follow their parents to the city to continue learning, there are also some 90 female migrant workers grew up in the city, but was later sent back to parents or back to the countryside school.

On the four factors that influence the status of individual characteristics, effects of 90 female migrant workers work status, life status and willingness to integrate the city into the city, based on the reference information, we analyzed the influence of effect.

We come up with some theoretical hypotheses:

(1) The growth of the age contributes to the integration of the female migrant workers in the city;

(2) Higher education level is helpful to the integration of urban migrant workers;

(3) Higher monthly income level is helpful to the integration of urban migrant workers;

(4) A certain length of time to help migrant workers into the city of 90 female migrant workers;

(5) All kinds of training to participate in enterprise organizations contribute to the integration of urban women;

(6) The signing of labor contracts with enterprises will contribute to the integration of urban migrant workers;

(7) The signing of social insurance contributes to the integration of the urban migrant workers;

(8) The frequent contact with neighbors and citizens will help the urban integration of female migrant workers;

(9) Higher urban life satisfaction is useful to the integration of urban migrant workers.

The degree of false "city settlement intention" as an index to measure the migrant workers into the city, in order to verify this assumption, we establish the econometric model of migrant workers under the city's willingness to settle down, and then an empirical analysis of the relationship between these factors and the willingness of migrant workers settled between the city.

According to the existing literature, the relevant control variables include: individual characteristic variables of migrant workers, such as age, cultural level; two is the variable working conditions of migrant workers, including monthly income, working time, training status, whether there is a labor contract, whether to sign insurance; three is the interaction of life variables of migrant workers such as, interaction with the neighbors; four are migrant workers to the city life satisfaction variables, namely on city life satisfaction. 


\section{Conclusions and recommendations}

(1) communication from the working and living conditions, 90 female migrant workers working time is not long, the overall quality is not high; although there is a strong awareness of rights, but the social security participation rate is low, regular employment awareness needs to be strengthened; the main living in the dormitory units, daily entertainment to play mobile phone or watch TV. Generally, with less city and the surrounding neighbor interaction;

(2) from the city into the situation, most of the 90 female migrant workers to the city life satisfaction is not high, although they are willing to continue to stay in the future city life, but the overall city integration degree is not high, between the city and people there is still a gap;

(3) from the Logistic regression analysis of the results, "education", "monthly income", "if there is a labor contract" and "city life satisfaction" four factors of 90 female migrant workers into the city will have a significant impact, including,

"Education", "if there is a labor contract" and "city of life satisfaction," these three factors may have a positive effect on their integration into the city, "monthly income" has a negative effect on their integration into the city, "age", "work time", "training", "whether to sign insurance" and "interaction with neighbors" for their integration into the city has no effect.[3]

(1) The advantages and disadvantages of the development of migrant workers' output will have a negative impact on the future of migrant workers

Migrant workers to the land, for 90 percent, there are missing relatives, acquainted with the environment and the lighter pressure of life, and therefore, compared with the strange city, the home has a greater attraction for them. Because do not adapt to the strange city, local customs and practices and habits, they cannot find a sense of belonging. Once the home of the economy, society and other improvements, they have a tendency to return to work and life. If there is no change in the various aspects of the home or worse, they will choose to continue to adhere to the city, or even a strong desire to settle the future of the city.

(2) The monthly income has a positive impact on the level and scope of the urban life of the female migrant workers

The survey showed that the women's monthly income increased, but the willingness to reduce their integration into the city, this is because the balance of their monthly income is difficult to meet the high level of the pursuit of life; but in the interview process, we have found that some female workers on income increase blessing positive attitude -- if the monthly income increase, remove all daily expenses, hands of spare cash will be relatively increased, the pressure of life will be relatively reduced, the city life satisfaction will increase.

(3) Whether the family life, leisure life and spiritual life have a positive impact on the level and depth of the female migrant workers in the city

In daily life, some 90 women put the leisure time for playing mobile phone at home and watch $\mathrm{TV}$; in leisure life, they put "with the mobile phone and the virtual world of communication" as a form of entertainment in daily communication; the object, they rarely communicate with city people, usually only in the "old guard" or "group of colleagues" in exchange. In a word, they are slowly isolating themselves from the city. We think they can only move out of their homes and actively communicate with people in the city, in order to improve the level and depth of urban integration.

(1) To speed up the reform of the household registration system, relax settled conditions

The current household registration system in China has resulted in the fact that people are not consistent in reality, especially the inequality of job-hunting and studying. Agriculture accounts and urban residents enjoy unequal rights. The fundamental reason is that the current household registration system carries too many additional features. In this case, the booklet is not only a manifestation of identity, but also a recognition of the right to enjoy resources, especially in employment and education in two areas. Therefore, to accelerate the reform of the household registration system, relax the conditions conducive to the entry of 90 female migrant workers to accelerate the pace of integration into the city.

(2) To create a dynamic household registration system 
China's household registration system reform has just started, is still in the trial stage. Japan's household registration system has been done to freedom of movement. Take the "household with the people" policy, the Japanese national walk arbitrary within the country, moved to a place, as long as the management authority registration and registration in the district can enjoy all the benefits and policies in the region.

If labor can flow freely between urban and rural areas, migrant workers will get equal rights with urban citizens through equal competition in employment, public services and other areas. This requires the government continues to play a role in the labor market construction, improve the service system for the labor market, continue to carry out effective education, promote 90 female migrant workers improve their skills, to achieve stable and regular employment.

The government should create a stable formal competition system and employment environment, cultivate the labor market, strengthen the labor market forecast, planning, regulation, legislation and supervision, and to make the institutionalization and standardization, strengthen the supervision of the implementation of "labor law" the relevant laws and regulations, to prevent the escape of formal employment, enterprises to simplify procedures 90 female migrant workers employment guarantee stability and normality.

Vigorously develop the technical education and vocational education of the female migrant workers, and enhance the competitiveness and stability of their employment. In order to expand the occupation development space of migrant workers, the following measures can be taken: first, enterprises should carry out a variety of training activities, and the two are to increase the input of training.

Most of the 90 female migrant workers are still in the corner of the city life is relatively closed, and did not show this age should be lively, active, undeveloped state of interpersonal communication. Therefore, the expansion of the female migrant workers' social circle, the increase of their interaction with the municipal citizens, and the strengthening of the awareness of the city's master, will help to improve the urban integration.

(1) Cancel the employee dormitory and adopt the form of "housing subsidy"

At present, most of the enterprises choose to build the dormitory at the employee's residence. Nonetheless, this not only increases the cost of the enterprise, but also led to the staff curled up in a narrow circle of communication, the lack of communication with the city people. Therefore, we suggest that the enterprise should cancel the staff quarters, and take the "- for older workers without housing to take a one-time subsidies in the form of housing subsidies", take a monthly subsidy for new employees, for employees to take the basic subsidy plus a one-time subsidy.[4]

(2) To improve the participation of female migrant workers in the community construction

City Community in general by external groups and within groups: groups within the general for the city residents, they have the absolute right to speak, but will not fully consider the specific position of internal and external groups; external groups mainly migrant workers, they cannot touch and affect the community's core system, only in the community on the edge, only passively an internal group oriented decision. Therefore, we believe that the community should be regarded as an important group of migrant workers, migrant workers and urban residents to encourage the formation of a certain proportion of the Commission, so that migrant workers and urban residents to jointly contribute to the governance of the community.

\section{Acknowledgment}

Fund Project: 2016 annual general project of Social Science Association of Zhejiang Province, the project number 2016N24Y, the results of the research on the daily social intercourse pattern of female migrant workers.

\section{References}

[1] Wangshu R. An Investigation into the Cultural Life of Migrant Workers in Urban-rural Communities: A Case Study of Shaoxing in Zhejiang Province [J]. Urban Insight, 2011. 
[2] Tingting, WANG. An Empirical Study on the Social Integration of Young Migrant Workers: A Case Study of Nanjing City [J]. Asian Agricultural Research, 2016, 08(3):44-46.

[3] Le A T K, Pham L T L, Lan H V, et al. Health services for reproductive tract infections among female migrant workers in industrial zones in Ha Noi, Viet Nam: an in-depth assessment[J]. Reproductive Health, 2012, 9(1):4.

[4] Yuleduor H. An investigation into service delivery at eco-tourism sites in Ghana: a case study of Mole National Park [J]. Economic Record, 2009, 88(282):425-439.

[5] Kun Jing (1979 -), female, Liaoning, Benxi, College of Economy and Trade management, Quzhou University lecturer, $\mathrm{PhD}$, mainly engaged in social governance, public policy research. Contact person;

[6] Qifeng Sun (1995-), male,2014 Undergraduate College of Economy and Trade management, Quzhou Universitystudents in reading, the main study and research of human resource management;

[7] Lingxiao Liang (1996-), female, 2014 Undergraduate College of Economy and Trade management, Quzhou Universitystudents in reading, learning and Research on human resource management. 